\title{
On the Anomalies in ULF Magnetic Field Variations Prior to the 2008 Sichuan Earthquake
}

\author{
Qi Li', Alexander Schekotov², Tomokazu Asano3 ${ }^{3}$, Masashi Hayakawa ${ }^{3,4,5}$ \\ ${ }^{1}$ Institute of Geophysics, China Earthquake Administration, Beijing, China \\ ${ }^{2}$ Institute of Physics of the Earth, Russian Academy of Sciences, Moscow, Russia \\ ${ }^{3}$ Earthquake Analysis Laboratory, Information Systems Inc., Minato-ku, Japan \\ ${ }^{4}$ Hayakawa Institute of Seismo Electromagnetics, Co. Ltd., University of Electro-Communications (UEC), Chofu, \\ Japan \\ ${ }^{5}$ UEC, Advanced Wireless Communications Research Center, Chofu, Japan \\ Email: hayakawa@hi-seismo-em.jp
}

Received 25 February 2015; accepted 12 March 2015; published 14 April 2015

Copyright (C) 2015 by authors and Scientific Research Publishing Inc.

This work is licensed under the Creative Commons Attribution International License (CC BY).

http://creativecommons.org/licenses/by/4.0/

(c) (i) Open Access

\section{Abstract}

There have been reported several papers on the ionospheric $F$ region perturbations prior to the 2008 Sichuan earthquake (EQ) (magnitude 8.0), but it seems that very few reports have been published on the characteristics of ground-based ULF (ultra low frequency) magnetic field variations for this EQ. This paper deals with two different aspects of ground-based ULF magnetic field variations: 1) ULF radiation from the lithosphere, and 2) depression of ULF horizontal magnetic field as a signature of lower ionospheric perturbations. ULF data from two Chinese stations [Chengdu (epicentral distance, $80 \mathrm{~km}$ ) and Xichang (about $300 \mathrm{~km}$ away from the EQ epicenter)] are analyzed, with paying attention to the local nighttime period (LT $=22$ h to $02 \mathrm{~h}, \mathrm{UTC}=14 \mathrm{~h}$ to $18 \mathrm{~h}$ ) in order to avoid man-made noise. We have analyzed powers of the horizontal component $\left(\mathrm{H}^{2}\right)$, vertical component $\left(\mathrm{Z}^{2}\right)$, polarization as their ratio $\left(\mathrm{Z}^{2} / \mathrm{H}^{2}\right)$, depression of the horizontal component (as an inverse of horizontal magnetic field component power, $1 / \mathrm{H}^{2}$ ) and $\delta$ Dep as a variation of depression at a particular frequency of $0.01-0.02 \mathrm{~Hz}(10-20 \mathrm{mHz})$. It is then found that there seems no clear signature of lithospheric ULF radiation. Whilst, the most evident fact is the finding of depression of ULF horizontal magnetic field at Chengdu a few days before the Sichuan EQ, which suggests that the lower ionosphere was perturbed before the EQ. The characteristics of the lower ionospheric perturbations are compared with those of upper ionospheric perturbations reported before.

\section{Keywords}

Earthquake, Earthquake Prediction, ULF Magnetic Variation, Lithospheric ULF Radiation, 


\section{ULF Depression}

\section{Introduction}

There has been accumulated a huge amount of evidence on the presence of electromagnetic precursors to the earthquakes (EQs) during the last few decades [1]-[6]. Some of those precursors are considered to be very promising for the short-term EQ prediction, especially perturbations in the lower ionosphere [7] and in the upper F region [8], because there have been established close statistical correlations between those ionospheric perturbations and EQs based on the long-term data. Furthermore, much progress has been achieved on the mechanisms of those different seismogenic effects, though not completely understood [5] [6].

In addition to the statistical studies, case studies for some EQs are still very important to understand the whole view of different electromagnetic signatures and then the lithosphere-atmosphere-ionosphere (LAI) coupling mechanism. We take the 2008 Sichuan EQ in China here as one of the most destructive EQs during the last decade. Several papers have already been published on this Sichuan EQ [9]-[13]. These are all based on the observational results on the perturbations in the upper ionosphere (F region) from the ground-based ionospheric sounders and GPS TEC measurements. Further studies on the perturbations on electron density, $\mathrm{O}^{+}$densities, ULF and ELF wave activity in the ionosphere have been performed by using the in-situ observations by different authors including [14]-[18]. As compared with various electromagnetic and plasma anomalies in association with the 2008 Sichuan EQ, there have been very few reports on the ground-based wave measurements. Especially, the analysis of geomagnetic ULF data is very lacking [19], so that this paper presents our results of extensive analyses on the variation of ground-based ULF magnetic field changes.

As is known, lithospheric ULF radiation has been observed prior to large EQs, such as Spitak EQ [20] [21], Loma Prieta EQ [22], and Guam EQ [23]. Recent studies on lithospheric ULF radiation have been summarized in [24] [25]. Another new nonconventional effect in ULF is discovered by Schekotov et al. [26] [27], which is vice versa of the above lithospheric radiation. That is the depression of ULF horizontal magnetic field component before an EQ, which is explained in terms of the enhanced absorption of magnetospheric ULF waves through the perturbed lower ionosphere [28]. This effect of seismo-ionospheric signatures has been recently confirmed even for the 2011 Tohoku EQ [28] [29]. These two aspects in ULF are treated together, by using the ULF data.

\section{Description of the Sichuan EQ and of the ULF data}

The 2008 Sichuan EQ or the Great Sichuan EQ happened at 02:28:01 pm Chinese Standard Time (or 06:28:01 UTC) on 12 May 2008 in the Sichuan province. Its magnitude was Ms = 8.0 (or Mw = 7.9) and its depth was 19 $\mathrm{km}$. This EQ had a lot of casualties; about 70,000 people were killed, and about 18,000 were left missing.

The epicenter of this EQ is located at the geographic coordinates $\left(31^{\circ} 01^{\prime} 05^{\prime \prime} \mathrm{N}, 103^{\circ} 36^{\prime} 05^{\prime \prime} \mathrm{E}\right)$, which is shown in Figure 1 as the center of the largest circle. This EQ is also known as Wenchuan EQ after its epicentral location in the Wenchuan County, Sichuan, but we call it "Sichuan EQ" in this paper.

The EQ epicenter was $80 \mathrm{~km}$ west-northwest of Chengdu, the provincial capital. The EQ was felt also in nearby countries and as far away from both Beijing and Shanghai (1500 and $1700 \mathrm{~km}$ respectively away from the epicenter), where office buildings swayed with tremor. Strong aftershocks, some exceeding the magnitude 6 , continued to hit the area even months after the main shock as shown in Figure 1 by several circles, causing new casualties and damage.

Figure 1 illustrates the locations of two stations of observing ULF magnetic field variations: Chengdu (abbreviated as CDP) and Xichang (XIC) as black diamonds. The magnetometer at those stations are of the conventional fluxgate type, and its sampling frequency is $1 \mathrm{~Hz}$. The resolution in ULF measurement is $0.1 \mathrm{nT}$.

\section{Data Quality Analysis}

The subjects of seismogenic effects using ULF data are, 1) seismogenic ULF radiation from the lithosphere, and 2) depression of ULF magnetic fields (horizontal component) as a signature of lower ionospheric perturbations. 


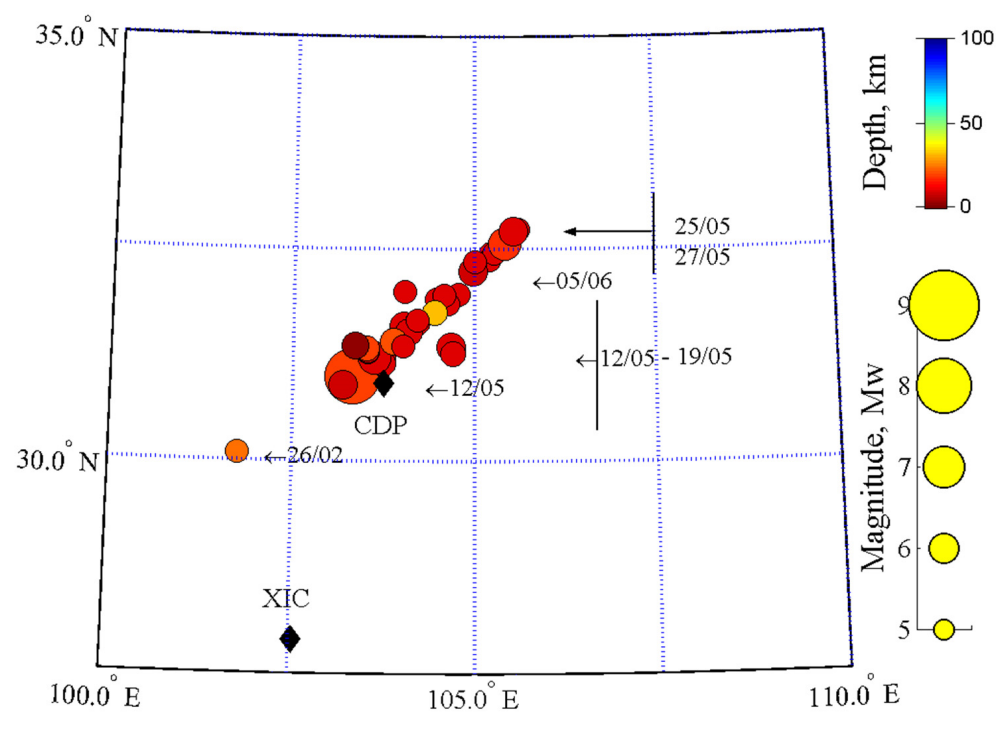

Figure 1. Map of the region with EQs and ULF observation stations. The center of the largest circle is the epicenter of the 2008 Sichuan EQ, and other several circles, its aftershocks. Two ULF stations are indicated by black diamonds: Chengdu (abbreviated as CDP) and Xichang (XIC).

The success of signal detection is known to depend not only on the nature and amplitude of observed signals, but also on the level of interferences at a station. The latter phenomenon seems to be very important especially in the case of studying field depression, when its value depends on minimal values of the magnetic field.

Figure 2(a) and Figure 2(b) illustrate examples of ULF signal in time and frequency domains on a particular day of 15 April 2008 at the two stations: CDP (a) and XIC (b). Top panels illustrate one-day evolutions of ULF magnetic field (horizontal component $\mathrm{H}$ ) in a particular frequency range of $10-50 \mathrm{mHz}$ at those two stations. The second panels correspond to the vertical $\mathrm{Z}$ component filtered in the same frequency range. The third panels illustrate the dynamic (frequency-time) spectra of $\mathrm{H}$ component at the two stations in the frequency range of $\mathrm{f}=$ 3 - $100 \mathrm{mHz}$. The bottom two refer to the corresponding spectra of $\mathrm{Z}$ component. As you can see from these dynamic spectra, they suggest high interferences, in general, in the form of strong pulses which occur very regularly every hour and caused by ionospheric sounding transmitters. It seems that the level of interferences is higher at XIC than at CDP. The background level at these stations indicates not only strong pulses, but also some noise-like signals even between those pulses. Position of the local midnight LMN $=24$-Lon/15 is shown by the vertical dashed lines; here Lon is the longitude of the site. It is the time when depression may reach maximal values [26].

Figure 3 illustrates a comparison of spectra of the horizontal magnetic field $(\mathrm{H})$ averaged over nighttime on the same day at those stations. The nighttime interval is defined by LT $=22 \mathrm{~h}$ to $02 \mathrm{~h}$ (UT = $14 \mathrm{~h}-18 \mathrm{~h}$ ), and the spectra averaged over night in Figure 3 is estimated on the basis of the information only between the pulsed interferences. Also the data from a Japanese standard magnetic observatory, Kakioka (KAK) (geographic coordinates, $36^{\circ} 13^{\prime} 56^{\prime \prime} \mathrm{N}, 140^{\circ} 11^{\prime} 11^{\prime \prime} \mathrm{E}$ ) on the same day are plotted in Figure 3 for the sake of comparison. The interference is found to be much higher at Chinese stations than at Kakioka, especially in the frequency range above $0.01 \mathrm{~Hz}$. Because this frequency range above $0.01 \mathrm{~Hz}$ is known to be optimal in the study of ULF depression [3] [26] [27], this will cause some uncertainties on the possible results on the ULF depression.

\section{Analysis Results}

Figure 4 and Figure 5 illustrate the temporal evolutions of magnetic field characteristics at both stations (CDP and XIC) for an interval from January to June, 2008. We tried to analyze as long period as possible, but the observation itself at CDP started in the beginning of January 2008. Moreover some of intervals of data were lost due to extreme interferences. They are marked by horizontal dashed red lines. In each figure, the top panel shows the variations of seismic activity (Kls) (as a function of EQ magnitude and epicentral distance [3]) and geomagnetic activity (Dst) (in nT). The magnetic field intensity (or power) (either horizontal $\left(\mathrm{H}^{2}\right)$ or vertical 

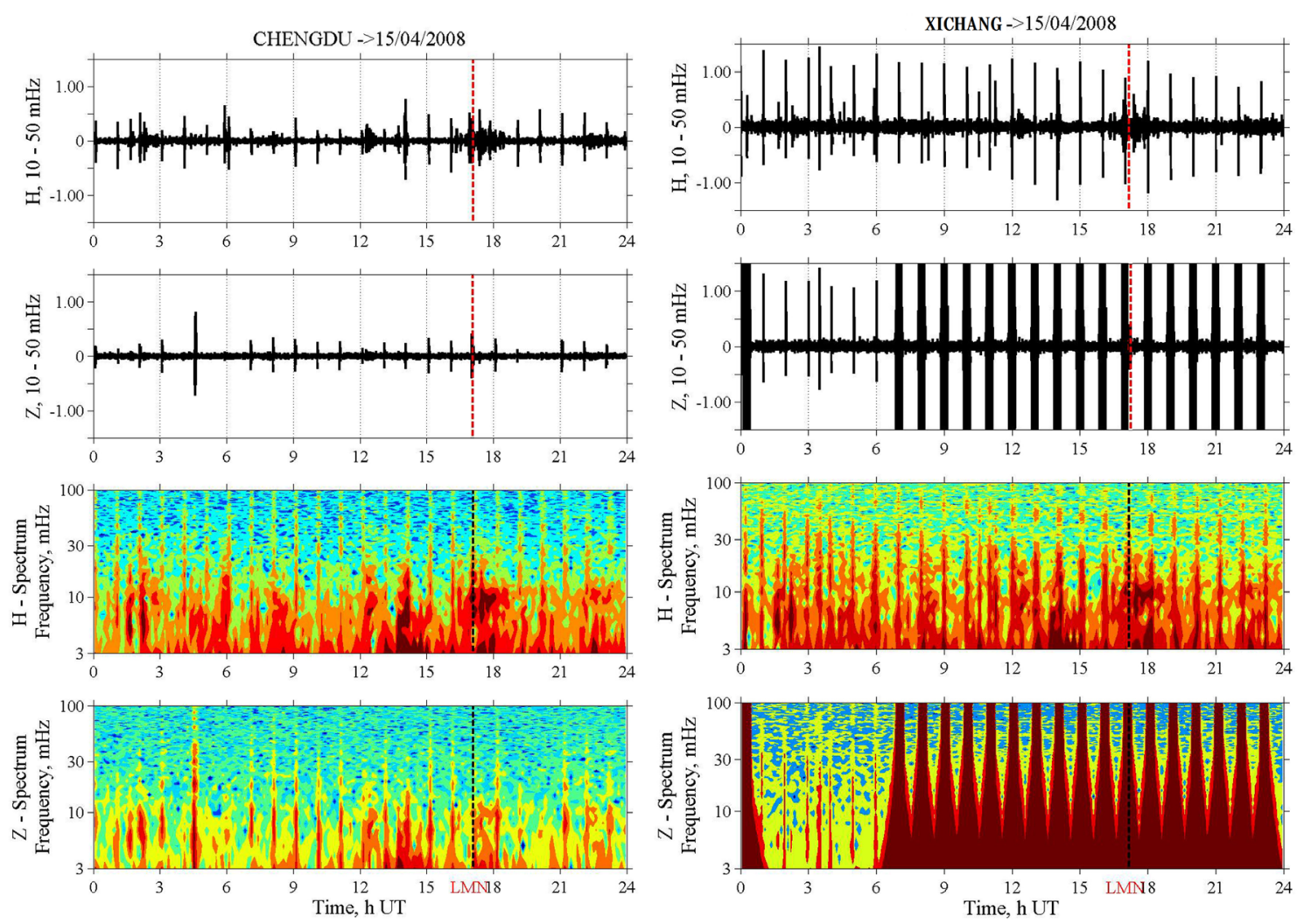

(a)

(b)

Figure 2. Examples of daily ULF background in CDP (a) and XIC (b) on a particular day of 15 April 2008. Top panels refer to the $\mathrm{H}$ component (at $10-50 \mathrm{mHz}$ ), the second two, the $\mathrm{Z}$ component (at the same frequency), the third two represent the dynamic spectra, and the bottom two refer to the $\mathrm{Z}$ component.

$\left(Z^{2}\right)$ ) is the one averaged over the above nighttime interval between the pulsed interferences, so that we have one datum per day. The second and third panels refer to the vertical $\left(\mathrm{Z}^{2}\right)$ and horizontal $\left(\mathrm{H}^{2}\right)$ magnetic field components, respectively. The fourth refers to the polarization as defined by [23] as the ratio of vertical to horizontal components $\left(\mathrm{Z}^{2} / \mathrm{H}^{2}\right)$. The fifth and sixth panels illustrate magnetic field depression equal to the inverse of horizontal magnetic field $\left(1 / \mathrm{H}^{2}\right)$ and the variation of ULF depression ( $\delta$ Dep) respectively. The definition of $\delta$ Dep is given in [27] [30], but it is the ratio of daily variation of depression relative to its mean value for previous $\mathrm{N}$ days to the mean value. In other words it is a normalized variation of depression. In our case $\mathrm{N}$ is taken equal to 30 days. The frequency band is $0.01-0.02 \mathrm{~Hz}(10-20 \mathrm{mHz})$ after the extensive comparison of results in different frequency ranges. We have applied a special algorithm of data processing only to the intervals between the pulsed interferences. Moments of the possible foreshock which occurred on 26 February and the main shock on 12 May, 2008 are shown by vertical red dashed lines.

We summarize the observational facts as follows from Figures 3-5.

1) The obtained flat spectra at the Chinese stations at the frequencies larger than $0.01 \mathrm{~Hz}(10 \mathrm{mHz})$ make it probably more difficult for us to detect the ULF depression. Those interferences may be caused by not only local sources including PCs, pulsed power supplies etc., but also by inappropriate installation of sensors.

2) Pulsed interferences are likely to be caused by a local ionospheric sounding transmitter.

3) High level of interferences does not give a possibility to estimate a comparative value of depression. We conclude that the level of depression at XIC is always smaller due to the higher level of background at this station.

4) Variation of vertical component $(Z)$ is not found to exhibit any clear peculiarities.

5) Variation of horizontal component $(H)$ shows peaks 10 - 12 days before the February $25 \mathrm{EQ}(\mathrm{M}=5.1)$ and before the relevant main shock on 12 May, respectively, especially notably at CDP.

6) Polarization does not exhibit any reliable peculiarities, but shows a peak just before the EQ. 


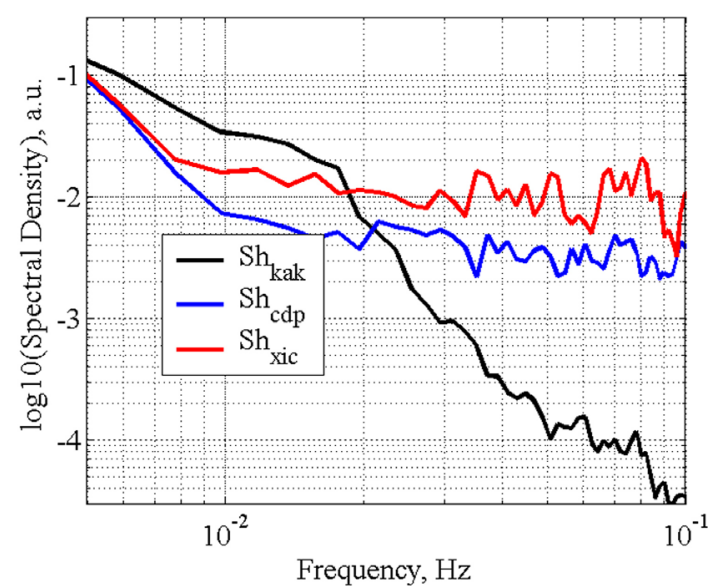

Figure 3. Nighttime averaged spectra of horizontal magnetic field at two Chinese stations (CDP and XIC) together with that at a Japanese station of Kakioka (KAK). Estimations of Chinese spectra are made only for the interval between the pulses.

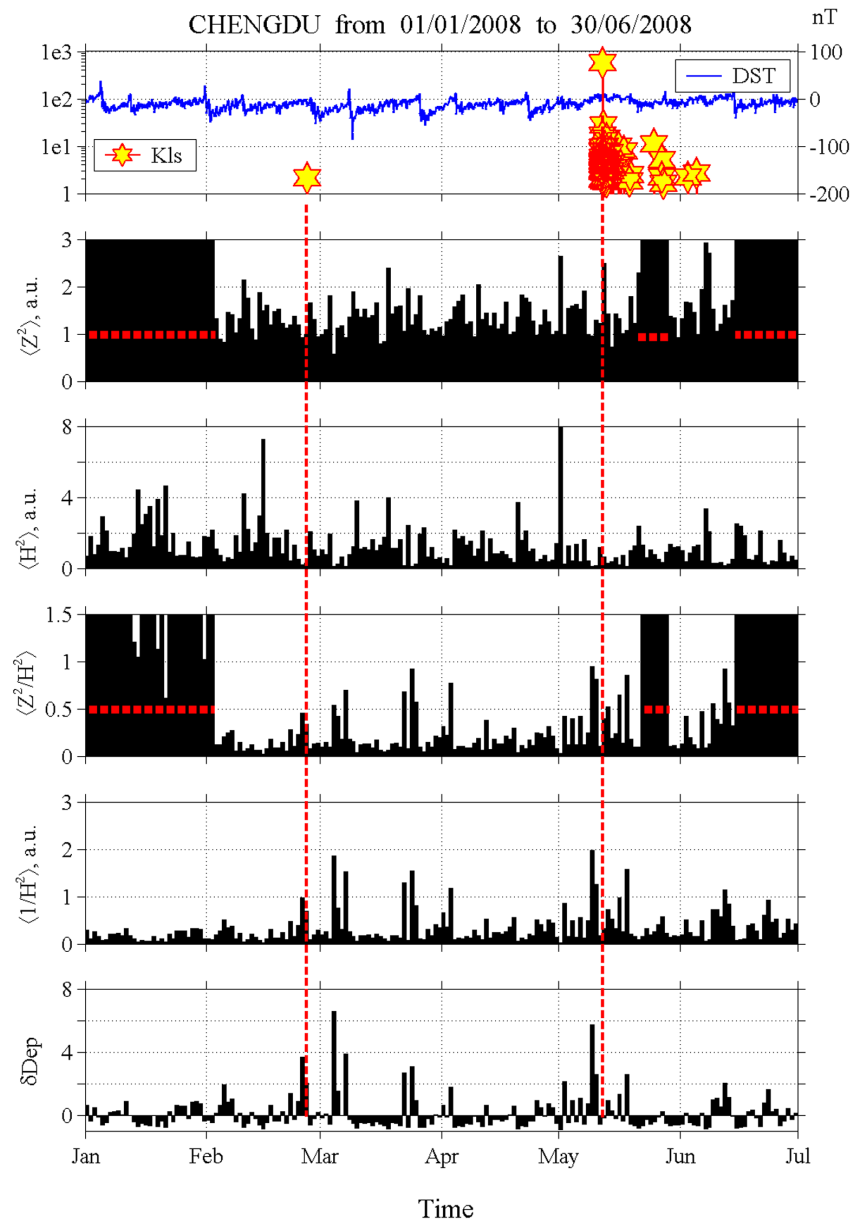

Figure 4. The result at CDP. Top panel illustrates the temporal evolutions of seismicity (Kls) and geomagnetic activity Dst (in $\mathrm{nT}$ ). The second and third panels are the temporal evolutions of the powers of vertical $\left(\mathrm{Z}^{2}\right)$ and horizontal $\left(\mathrm{H}^{2}\right)$ magnetic field components. The fourth panel corresponds to the polarization as the ratio of vertical to horizontal components $\left(\mathrm{Z}^{2} / \mathrm{H}^{2}\right)$. The fifth and the last panels refer to the temporal evolutions of $\mathrm{Dh}$ as the inverse of $\mathrm{H}^{2}$ and the corresponding $\delta$ Dep, respectively. The time intervals of unreliable results due to the incorrect data by high interferences, are indicated with red dashed horizontal lines. Then, the moments of the (possible) foreshock occurred on 26 February and the main shock on 12 May are shown by vertical red dashed lines. 


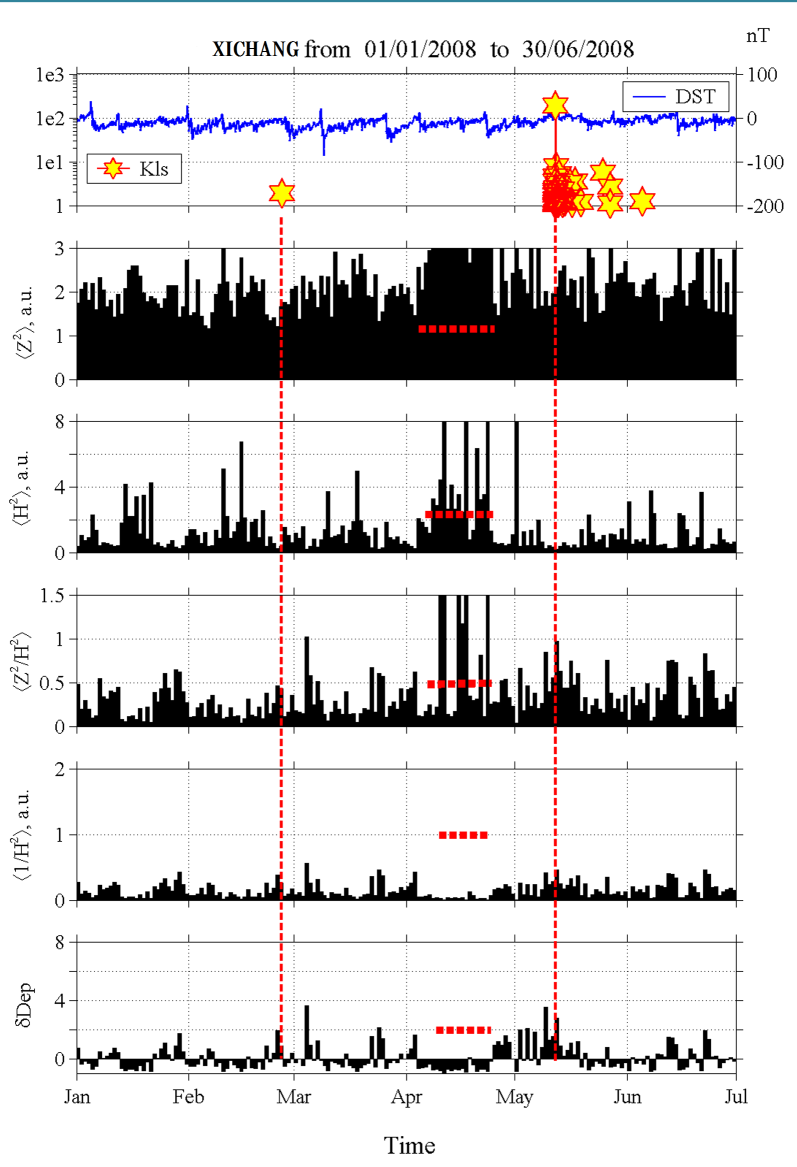

Figure 5. The same as Figure 4, but for XIC.

7) Depression and $\delta$ Dep are found to show a significant increase in the vicinity of (just before, a few days before) the EQs occurred on 26 February and the main shock on 12 May.

It is very unfortunate that the noise level or interference at our two Chinese stations is considerably higher as compared with that in Japan (KAK), especially at the higher frequency range above $0.01 \mathrm{~Hz}(10 \mathrm{mHz})$. The most optimal frequency range to detect the ULF depression is found to be $0.03-0.05 \mathrm{~Hz}(30-50 \mathrm{mHz})$ [3] [26], so that it is unlikely that high noise levels at our two Chinese stations are favorable for the study of ULF depression, so that we are obliged to choose the appropriate frequency to study both effects of lithospheric radiation and ULF depression.

\section{Conclusions and Discussion}

Using the ULF data during several months around the 2008 Sichuan EQ, we performed detailed studies of temporal evolutions of magnetic field variations; horizontal $\left(\mathrm{H}^{2}\right)$, vertical $\left(\mathrm{Z}^{2}\right)$, inverse horizontal $\left(1 / \mathrm{H}^{2}\right)$, and ULF depression $(\delta \mathrm{Dep})$ in different frequency bands. After having analyzed different frequency ranges, we have shown only the results at a particular frequency of $0.01-0.02 \mathrm{~Hz}(10-20 \mathrm{mHz})$ because we could identify something in this frequency range and also this range seems to be the upper limit with smaller interferences as shown in Figure 3. We know that there are two possible effects in ULF range: 1) lithospheric radiation from the EQ hypocenter, and 2) depression of horizontal component as an ionospheric signature. Main conclusions from the present analyses can be summarized as follows for each item.

1) There is no clear (or definite) evidence on the presence of lithospheric ULF emissions.

2) A significant effect seems to be detected in the ULF depression and $\delta$ Dep a few days before the main shock on 12 May.

First, we discuss the first topic of lithospheric ULF radiation. When studying the radiation, we try to find anomalous enhancement in the magnetic field components. We have found that the horizontal magnetic field 
component $(\mathrm{H})$ exhibited, at both stations, peaks prior to the 26 February EQ $(\mathrm{M}=5.1)$ (probably a foreshock) and also before the main shock on 12 March. These peaks are found to take place only on a particular day as summarized as Point (5) and to be simultaneous at the two stations of CDP and XIC as seen from Figure 4 and Figure 5. Also, the vertical component (Z) showed the corresponding peak on the same day. All of these suggest that these peaks are not local, but rather global in nature over the spatial scale of at least $300 \mathrm{~km}$. The most probable origin of such a global disturbance of this spatial scale may be the effect of geomagnetic storms, but the comparison with Dst in Figure 4 shows no connection between the two. So, though the origin of these peaks is not well understood, it is not probable that they are related to seismic activity. Then, it seems that the vertical (Z) component at CDP does not show any significant changes, and no clear signature is seen at XIC. This inference might be furthermore supported by the previous observational fact [24] that the range of detection of seismogenic ULF radiation is on the order of $100 \mathrm{~km}$ for an EQ with $\mathrm{M}=7$, though there is no information on this value for $M=8$. Of course, there is no reason to deny that those peaks are of seismic origin. Whereas, the polarization as suggested by [23] is found to be very effective in distinguishing seismogenic from other effects including geomagnetic activity [31], and it shows a significant peak a few days before the EQ. This enhancement seems to be significant, but not so conspicuous.

The most evident observational result from this paper is the ULF depression (the second topic) as shown as $\delta$ Dep in both Figure 4 and Figure 5. We consider its evolution in a separate Figure 6. Herein top panel shows the evolution of seismicity and geomagnetic activity and next two panels are the copies of bottom panels of Figure 4 and Figure 5. They reflect the evolutions of $\delta$ Dep at the stations CDP and XIC accordingly. Especially, at the station (CDP) closest to the EQ epicenter, we have observed clear depression a few days before the main shock on 12 May, and its value amounts to about 6. Furthermore, this ULF depression seems to be seen on the same days even at the station of XIC which is about $300 \mathrm{~km}$ from the EQ epicenter. Then, the similar ULF depression is seen at the station of CDP for the February $26 \mathrm{EQ}$, just before the EQ, and this kind of behavior is also seen at the station of XIC. The way of appearance of these depression effects seems to be a natural phenomenon, and these results would suggest that those are a seismogenic effect. This February EQ is likely to be a precursor to the following seismic events, and the growth of depression at CDP is characterized as an onset of seismic activity in this region. Finally, a few days before the main shock we observed a precursor to the main shock a few days before the EQ as a depression in ULF horizontal magnetic field as a signature of lower ionospheric perturbations.

There has been published one paper [19] on the ULF variations for this Sichuan EQ. The ULF data at several

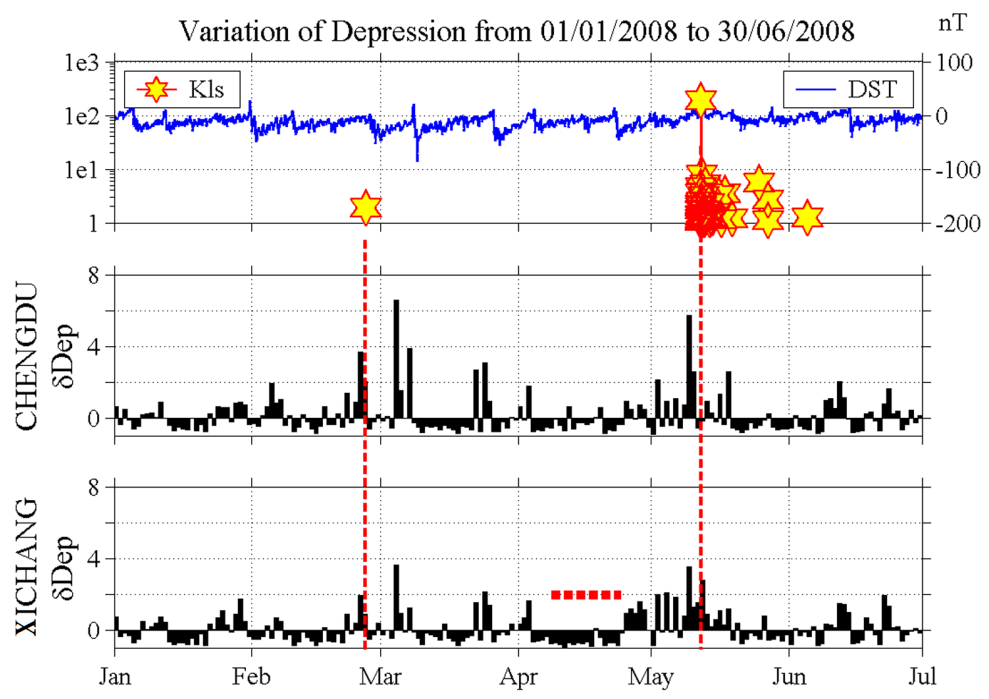

Figure 6. Evolutions of $\delta$ Dep at two stations (CDP and XIC) during a whole period of January-June, 2008. The top panel illustrates the temporal evolution of seismic (Kls) and geomagnetic (Dst) activities. Again vertical red dashed lines indicate the moments of the foreshock on 26 February and the main shock on 12 May. 
stations including the same station of CDP as in this paper, were analyzed, and his conclusion was as follows. He applied the previous analysis methods such as polarization [23] and wavelet method, but no clear anomalous magnetic variations were observed for this EQ. The only one thing seeming to be associated with the EQ might be some anomalous variations in the power of second eigenvalue in the principal component analysis in January-March, 2008. As the most important point when analyzing the ULF variations in a noisy station, we have to pay the greatest attention to the study of noise spectra. Our study in this paper has yielded nearly the same result as [19]: no clear and definite signature of lithospheric ULF radiation for this 2008 Sichuan EQ, with the conventional statistical analysis as in this paper. We need more sophisticated analysis methods based on critical concept, such as fractal analysis [32] and natural time analysis [33]-[35]. However, we have succeeded in identifying the depression of ULF horizontal magnetic field as the signature of lower ionospheric perturbation, which occurs a few days before the EQ.

Though there have been published several papers on the ionospheric plasma and wave characteristics before the Sichuan EQ on the basis of DEMETER satellite data [15]-[17] [36], the ground-based observation is definite to provide us with the detailed temporal evolution of different seismogenic phenomena when the number of stations is sufficient to form a network. We will compare our results on the lower ionosphere with those in the upper (F region) ionosphere based on the ground-based ionospheric measurements. Based on the network of ionosonde sounding, Liu et al. [10] have found that anomalies in foF2 occurred on 9 May, 3 days before the EQ. Then, Liu et al. [11] have indicated that the anomaly in TEC observation showed an anomaly on 9 and 10 May, a few days before the EQ. The same conclusion was obtained by [37]. The most evident result from this paper is the depression of ULF horizontal magnetic field on 9, 10 May, a few days before the EQ. This result is known to be the consequence of the perturbation in the lower ionosphere [9]. With taking into account these results altogether, we may come to the conclusion that the ionosphere both in the lower part and in the upper $\mathrm{F}$ region, is perturbed nearly on the same days before the Sichuan EQ.

To our knowledge, this paper is likely to be the first attempt to compare the perturbations both in the lower and upper ionosphere before an EQ. The normal lead time of seismic-related F layer perturbation is 3 - 5 days [8], whereas that for the lower ionospheric perturbation is about one week [7]. So, it seems that there may exist a significant difference of a few days between the lower and upper ionospheric perturbations. However, we have found close synchronism in temporal evolutions of ionospheric perturbations both in the lower and upper ionosphere, at last, for this Sichuan EQ, suggesting a common agent for both lower and upper ionospheric perturbations. This would provide us with a hint on the generation mechanism of seismo-ionospheric perturbations as discussed in [38].

\section{Acknowledgements}

The authors are grateful to the referees for their useful suggestions on our paper.

\section{References}

[1] Hayakawa, M. and Molchanov, O.A. (2002) Seismo Electromagnetics: Lithosphere-Atmosphere-Ionosphere Coupling. TERRAPUB, Tokyo, $477 \mathrm{p}$.

[2] Pulinets, S. and Boyarchuk, K. (2004) Ionospheric Precursors of Earthquakes. Springer, Berlin, 315 p.

[3] Molchanov, O.A. and Hayakawa, M. (2008) Seismo-Electromagnetics and Related Phenomena: History and Latest Results. TERRAPUB, Tokyo, 189 p.

[4] Hayakawa, M. (2009) Electromagnetic Phenomena Associated with Earthquakes. Transworld Research Network, Trivandrum, $279 \mathrm{p}$.

[5] Hayakawa, M. (2012) The Frontier of Earthquake Prediction Studies. Nihon-Senmontosho-Shuppan, Tokyo, 794 p.

[6] Hayakawa, M. (2013) Earthquake Prediction Studies: Seismo Electromagnetics. TERRAPUB, Tokyo, 168 p.

[7] Hayakawa, M., Kasahara, Y., Nakamura, T., Muto, F., Horie, T., Maekawa, S., Hobara, Y., Rozhnoi, A., Solovieva, M. and Molchanov, O.A. (2010) A Statistical Study on the Correlation between Lower Ionospheric Perturbations as Seen by Subionospheric VLF/LF Propagation and Earthquakes. Journal of Geophysical Research, 115, A09305. http://dx.doi.org/10.1029/2009JA015143

[8] Liu, J.Y. (2009) Earthquake Precursors Observed in the Ionospheric F-Region. In: Hayakawa, M., Ed., Electromagnetic Phenomena Associated with Earthquakes, Transworld Research Network, Trivandrum, 187-204.

[9] Zhao, B., Wang, M., Yu, T., Wan, W., Lei, J., Liu, L. and Ning, B. (2008) Is an Unusual Large Enhancement of Io- 
nospheric Electron Density Linked with the 2008 Great Wenchuan Earthquake? Journal of Geophysical Research, 113, A11304. http://dx.doi.org/10.1029/2008JA013613

[10] Liu, J.Y., Chen, Y.I., Chen, C.H., Liu, C.Y., Chen, C.Y., Li, J.Z., Xia, T.Q., Oyama, K.I., Hattori, K. and Lin, C.H. (2009) Seismoionospheric GPS Total Electron Content Anomalies Observed before the 12 May 2008 Mw 7.9 Wenchuan Earthquake. Journal of Geophysical Research, 114, A04320. http://dx.doi.org/10.1029/2008JA013698

[11] Liu, C.Y., Liu, J.Y., Chen, W.S., Li, J.Z., Xia, Y.Q. and Cui, X.Y. (2010) An Integrated Study of Anomalies Observed before Four Major Earthquakes: 2004 Sumatra M9.3, 2006 Pingtung M7.0, 2007 Chuetsu Oki M6.8, and 2008 Wenchuan M8.0. Journal of Asian Earth Sciences, 41, 401-409. http://dx.doi.org/10.1016/j.jseaes.2010.05.012

[12] Pulinets, S.A., Boudur, V.G., Tsidilina, M.N. and Gaponova, M.V. (2010) Verification of the Concept of Seismoionospheric Coupling under Quiet Heliogeomagnetic Conditions, Using the Wenchuan (China) Earthquake of May 12, 2008, as an Example. Geomagnetism and Aeronomy, 50, 231-242. http://dx.doi.org/10.1134/S0016793210020118

[13] Klimenko, M.V., Klimenko, V.V., Aakharenkova, I.E., Pulinets, S.A., Zhao, B. and Tsidilina, M.T. (2011) Formation Mechanism of Great Positive TEC Disturbances Prior to Wenchuan Earthquake on May 12, 2008. Advances in Space Research, 48, 488-499. http://dx.doi.org/10.1016/j.asr.2011.03.040

[14] Zhang, X., Shen, X., Liu, J., Ouyang, X., Qian, J. and Zhao, S. (2009) Analysis of Ionospheric Plasma Perturbations before Wenchuan Earthquake. Natural Hazards and Earth System Science, 9, 1259-1266. http://dx.doi.org/10.5194/nhess-9-1259-2009

[15] Sarkar, S. and Gwal, A.K. (2010) Satellite Monitoring of Anomalous Effects in the Ionosphere Related to the Great Wenchuan Earthquake of May 12, 2008. Natural Hazards, 55, 321-332. http://dx.doi.org/10.1007/s11069-010-9530-9

[16] Blecki, J., Parrot, M. and Wronowski, R. (2010) Studies of the Electromagnetic Field Variations in ELF Frequency Range Registered by DEMETER over the Sichuan Region Prior to the 12 May 2008 Earthquake. International Journal of Remote Sensing, 31, 3615-3629. http://dx.doi.org/10.1080/01431161003727754

[17] Walker, S.N., Kadirkamanathan, V. and Pokhotelov, O.A. (2013) Changes in the Ultra-Low Frequency Wave Field during the Precursor Phase to the Sichuan Earthquake: DEMETER Observations. Annales Geophysicae, 31, 1597-1603. http://dx.doi.org/10.5194/angeo-31-1597-2013

[18] Ryu, K., Parrot, M., Kim, S.G., Jeong, K.S., Chae, J.S., Pulinets, S. and Oyama, K.I. (2014) Suspected Seismo-Ionospheric Coupling Observed by Satellite Measurements and GPS TEC Related to the M7.9 Wenchuan Earthquake of 12 May 2008. Journal of Geophysical Research, 119, 10305-10323.

[19] Huang, Q.H. (2011) Retrospective Investigation of Geophysical Data Possibly Associated with the $\mathrm{M}_{\mathrm{s}} 8.0$ Wenchuan Earthquake in Sichuan, China. Journal of Asian Earth Sciences, 41, 421-427. http://dx.doi.org/10.1016/j.jseaes.2010.05.014

[20] Kopytenko, Y.A., Matiashvily, T.G., Voronov, P.M., Kopytenko, E.A. and Molchanov, O.A. (1990) Discovering of Ultra-Low-Frequency Emissions Connected with Spitak Earthquake and Its Aftershock Activity on Data of Geomagnetic Pulsations Observations at Dusheti and Vardzija. IZMIRAN Preprint N3, 888, 27 p.

[21] Molchanov, O.A., Kopytenko, Y.A., Voronov, P.M., Kopytenko, E.A., Matiashvili, T.G., Fraser-Smith, A.C. and Bernardy, A. (1992) Results of ULF Magnetic Field Measurements near the Epicenters of the Spitak $\left(M_{s}=6.9\right)$ and the Loma-Prieta $\left(\mathrm{M}_{\mathrm{s}}=7.1\right)$ Earthquakes: Comparative Analysis. Geophysical Research Letters, 19, 1495-1498. http://dx.doi.org/10.1029/92GL01152

[22] Fraser-Smith, A.C., Bernardy, A., McGill, P.R., Ladd, M.E., Helliwell, R.A. and Villard Jr., O.G. (1990) Low-Frequency Magnetic Field Measurements near the Epicenter of the $\mathrm{M}_{\mathrm{s}}$ 7.1 Loma-Prieta Earthquake. Geophysical Research Letters, 17, 1465-1468. http://dx.doi.org/10.1029/GL017i009p01465

[23] Hayakawa, M., Kawate, R., Molchanov, O.A. and Yumoto, K. (1996) Results of Ultra-Low-Frequency Magnetic Field Measurements during the Guam Earthquake of 8 August 1993. Geophysical Research Letters, 23, 241-244. http://dx.doi.org/10.1029/95GL02863

[24] Hayakawa, M., Hobara, Y., Ohta, K. and Hattori, K. (2011) The Ultra-Low-Frequency Magnetic Disturbances Associated with Earthquakes. Earthquake Science, 24, 523-534. http://dx.doi.org/10.1007/s11589-011-0814-2

[25] Hattori, K. (2013) ULF Geomagnetic Changes Associated with Major Earthquakes. In: Hayakawa, M., Ed., Earthquake Prediction Studies: Seismo Electromagnetics, TERRAPUB, Tokyo, 129-152.

[26] Schekotov, A., Molchanov, O.A., Hattori, K., Fedorov, E., Gladyshev, V.A., Belyaev, G.G., Chebrov, V., Sinitsin, V., Gordeev, E. and Hayakawa, M. (2006) Seismo-Ionospheric Depression of the ULF Geomagnetic Fluctuations at Kamchatka and Japan. Physics and Chemistry of the Earth, 31, 313-318. http://dx.doi.org/10.1016/j.pce.2006.02.043

[27] Schekotov, A., Fedorov, E., Molchanov, O.A. and Hayakawa, M. (2013) Low Frequency Electromagnetic Precursors as a Prospect for Earthquake Prediction. In: Hayakawa, M., Ed., Earthquake Prediction Studies: Seismo Electromagnetics, TERRAPUB, Tokyo, 81-99. 
[28] Hayakawa, M., Rozhnoi, A., Solovieva, M., Hobara, Y., Ohta, K., Schekotov, A. and Fedorov, E. (2013) The Lower Ionospheric Perturbation as a Precursor to the 11 March 2011 Japan Earthquake. Geomatics, Natural Hazards and Risk, 4, 275-287. http://dx.doi.org/10.1080/19475705.2012.751938

[29] Schekotov, A., Fedorov, E., Hobara, Y. and Hayakawa, M. (2013) ULF Magnetic Field Depression as a Possible Precursor to the 2011/3.11 Japan Earthquake. Journal of Atmospheric Electricity, 33, 41-51.

[30] Schekotov, A., Izutsu, I. and Hayakawa, M. (2015) On Precursory ULF/ELF Electromagnetic Signatures for the Kobe Earthquake on April 12, 2013. Journal of Asian Earth Sciences, in Press. http://dx.doi.org/10.1016/j.jseaes.2015.02.019

[31] Currie, J.L. and Waters, C.L. (2014) On the Use of Geomagnetic Indices and ULF Waves for Earthquake Precursor Signatures. Journal of Geophysical Research: Space Physics, 119, 992-1003. http://dx.doi.org/10.1002/2013JA019530

[32] Hayakawa, M. and Ida, Y. (2008) Fractal (Mono- and Multi-) Analysis for the ULF Data during the 1993 Guam Earthquake for the Study of Prefracture Criticality. Current Development in Theory and Applications of Wavelets, 2, 159-174.

[33] Varotsos, P.A. (2005) The Physics of Seismic Electric Signals. TERRAPUB, Tokyo, 338 p.

[34] Eftaxias, K., Potirakis, S.M. and Chelidze, T. (2013) On the Puzzling Feature of the Silence of Precursory Electromagnetic Emissions. Natural Hazards and Earth System Science, 13, 2381-2397. http://dx.doi.org/10.5194/nhess-13-2381-2013

[35] Hayakawa, M., Schekotov, A., Potirakis, S. and Eftaxias, K. (2015) Criticality Features in ULF Magnetic Fields Prior to the 2011 Tohoku Earthquake. Proceedings of the Japan Academy: Series B, 91, 25-30.

[36] Onishi, T., Berthelier, J.J. and Kamogawa, M. (2011) Critical Analysis of the Electrostatic Turbulence Enhancements Observed by DEMETER over the Sichuan Region during the Earthquake Preparation. Natural Hazards and Earth System Science, 11, 561-570. http://dx.doi.org/10.5194/nhess-11-561-2011

[37] Saradjian, M.R. and Akhoonzadeh, M. (2011) Prediction of the Date, Magnitude and Affected Area of Impending Strong Earthquakes Using Integration of Multi Precursors Earthquake Parameters. Natural Hazards and Earth System Science, 11, 1109-1119. http://dx.doi.org/10.5194/nhess-11-1109-2011

[38] Kamiyama, M., Sugito, M., Kuse, M., Schekotov, A. and Hayakawa, M. (2014) On the Precursors to the 2011 Tohoku Earthquake: Crustal Movements and Electromagnetic Signatures. Geomatics, Natural Hazards and Risk. http://www.tandfonline.com/doi/abs/10.1080/19475705.2014.937773 